\title{
Agency Construction and Navigation in Oral Narratives of English Learning by Chinese College English Majors
}

\author{
Qiuming $\operatorname{Lin}^{1}$ \\ ${ }^{1}$ Faculty of English Language and Culture, Guangdong University of Foreign Studies, Guangzhou, China \\ Correspondence: Qiuming Lin, Faculty of English Language and Culture, Guangdong University of Foreign \\ Studies, No. 2, Baiyundadaobei, Guangzhou, 510421, China. Tel: 86-137-9811-7687. E-mail: \\ linqiuming@gdufs.edu.cn
}

Received: July 24, 2017 Accepted: August 14, $2017 \quad$ Online Published: August 16, 2017

doi: 10.5539/elt.v10n9p161 URL: http://doi.org/10.5539/elt.v10n9p161

\begin{abstract}
The current study aims to investigate the discursive construction and navigation of agency in oral narratives of English learning by Chinese college English majors. Based on the theoretical framework integrating Bamberg et. al.'s theory of identity dilemma and Hallidayan systemic functional linguistics, the study has addressed two research questions: 1) How do the speakers construct different levels of agency in their narratives? 2) How do the speakers navigate among different levels of agency throughout their narratives? The research data comes from monthly-based individual interviews with the participants for one year, from which significant English-learning stories are selected. Then transitivity analysis and logico-semantic analysis are conducted to the stories clause by clause so as to find out the linguistic patterns for agency construction and navigation. The study has found that speakers construct different levels of agency with various transitivity patterns, and navigate the agency dilemma by moving back and forth among different levels of agency with various logico-semantic relations. It has also illustrated that agency is not a fixed entity that a speaker possesses, but constructed and negotiated dynamically by the speaker all the way through his/her narratives.
\end{abstract}

Keywords: learner agency, identity construction, oral narratives, transitivity, logico-semantic relation

\section{Research Motivation}

As an EFL teacher working for over ten years in GW, a key university in Southern China, the author has been listening to numerous English-learning stories told by her students. There are joyful stories, sad stories, ambitious stories, gloomy stories, and very often the author is deeply carried into their story world, cheered, grieved, inspired or depressed. From the stories they told and the way they told the stories, the author comes to understand how the English majors, as variously agentive beings, construct and negotiate their relationship to the social world across time and space through English learning.

Anyone who has listened to the students' stories can undoubtedly sense different degrees of agency in different stories, and very often, fluctuations of agency in one single story. But how exactly do the narrators position themselves and others as agentive or non-agentive in their story-telling? How do they alter these positionings through their accounts? What linguistic resources do they choose and deploy in agency making and negotiation? Having been trained as a linguist, the author realizes that such investigations must be engaged with proper linguistic techniques of analysis, especially for textual micro-analysis. Her training within systemic functional linguistics (SFL) has convinced her that its grammatics has considerable potential for such work. It provides a comprehensive tool-kit to bridge meaning and form, and for this particular study, to investigate the construction and navigation of agency through linguistic forms.

\section{Literature Review}

\subsection{Agency in Oral Narrative Discourse}

Ahearn (2001) suggests that it is important for scholars interested in agency to look closely at language and linguistic form. Oral talks are discursive practices in everyday conversation and interactions. They are more naturally and spontaneously occurring, and less consciously produced than written texts. Some scholars study agency in real-time conversations based on the assumption that agency is an interactive achievement (Strauss \& Xiang, 2006; Miller, 2010; Comparini, 2013; King, 2014). Others study agency in oral narratives, with the belief 
that oral narratives play a central role in the construction of social identities (Schiffrin, 1996). Oral narratives are not only tools for reflecting on people's lives, but constructive means for the creation of characters in space and time (Bamberg \& Georgakopoulou, 2008).

More and more scholars interested in language learner identity or learner agency have also employed narrative data in their studies. Barkhuizen (2013) suggests that narratives of language learning experience reflect the dynamic socio-cultural features embedded in the process of language acquisition. Learners' narratives have embodied the learning action and identity construction, so that they can reveal the relation between learners' agency and learners' identity. Qin (2015) investigates the English learning history of a college English student by adopting the narrative approach. The study finds the important roles agency and identity play in language learning and concludes that their interrelationship is non-linear. Agentive actions as the meditational force not only facilitate the identities construction but also vest them with situated nature.

However, most agency studies explored in oral narratives so far are content-based. They focus on the themes that merged in the talk, and the social and cultural discourses by which agency of the speaking subject is built on. In fact, agency can be studied more intensively by focusing on specific linguistic features, particularly from the lens of SFL.

\subsection{Agency from the Perspective of SFL}

Systemic functional linguistics (SFL) has been concerned with language as a system not only for carrying meaning, but also for creating meaning. Ideational function is one of the metafunctions of text in Hallidayan functional linguistics. Language provides a theory of human experience. People use language to talk about the world, either the external world - things, events, qualities, etc. - or our internal world - thoughts, beliefs, feelings, etc. This ideational function embodies two sub-functions, the experiential and the logical. From the experiential perspective, language comprises a set of resources for referring to entities in the world and the ways in which those entities act on or relate to each other. From the logical perspective, language comprises a set of resources for making different logical and semantic connections between messages.

On the one hand, agency construction is concerned with how the speakers make sense of themselves and of the context within which they move, or how they construe their lived experience, so it is mostly an experiential issue. On the other hand, agency navigation is concerned with how the speakers connect pieces of messages with different levels of agency into a coherent story, or how they manage the fluctuations of agency in their narratives, so it is a logical issue. Therefore, the analysis on these two issues in this research aims to "deconstruct" texts in terms of ideational function.

In SFL, the experiential function is realized by transitivity patterns, which is a means of conveying ideas about who acts, speaks, sees, reflects, etc. in individual clauses. An analysis of these patterns "helps readers to understand human interactions in social contexts and can be used to uncover ideological meanings within them" (Nguyen, 2012, p. 86). A study of transitivity allows for a close examination of the linguistic features that help to communicate subjectivity and agency. Within this framework, it is understood that active verbs can realize a variety of processes, which, in turn, constitute various types of agency.

Barker and Galasinski (2001) have dealt with problems of agency into a close micro-linguistic data analysis. They employ transitivity analysis and ergative analysis in SFL to investigate the conflict between the Ukrainians and the Poles during WWII. The current research is going to follow their study by applying a micro-discourse analysis to oral narrative data. But different from their analysis only to selected individual utterances, the current study is going to examine agency in each clause in the narratives and show the general pattern of agency features as well as agency fluctuations throughout the narratives.

\section{Theoretical Framework}

A theoretical framework has been built for the current research, mainly on the common ground of two theories: Bamberg et. al.'s theory of identity dilemma and Hallidayan systemic functional linguistics, both emphasizing the significance of linguistic choices. The former advocates that identity is discursively constructed, so identity construction is based on discursive choices. The latter holds that language is a system of choice, and meaning is made by linguistic choices in a complex network of systems. Based on this important common ground, the theories are integrated into a framework which serves as the theoretical foundation of the current research. The framework is illustrated by the following diagram (see Figure 1). 


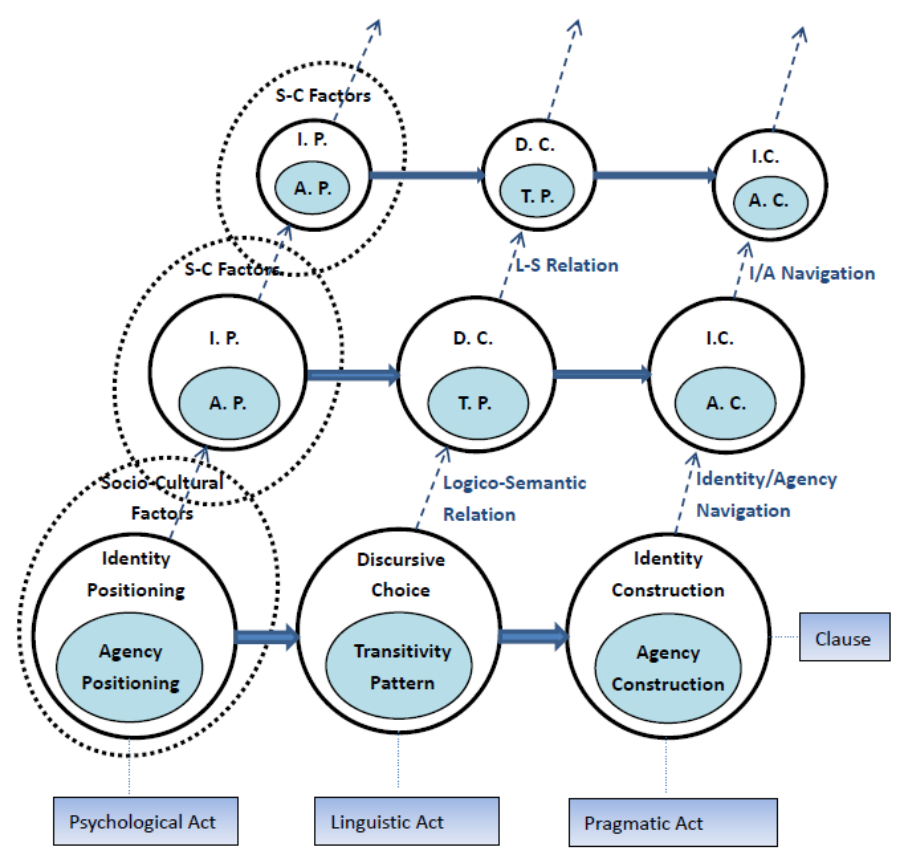

Figure 1. Theoretical framework for the research

When people give account of their lived experiences, the utterance of each clause in their narratives consists of three acts. The first act is identity positioning, which refers to how people make sense of themselves, how they place themselves in the three identity dilemmas (Bamberg et al., 2011). This is a psychological act, taking place in a socio-cultural setting, and influenced by the speaker's historical and cultural trajectory. As agency is a crucial component of identity, agency positioning is part of the act. Identity positioning will lead to discursive choice, which is the second act. This refers to picking discursive devices to give the accounts, which is a linguistic act. Among various discursive choices, there is the choice of transitivity pattern, through which agency is realized. After the utterance of the clause, a certain identity of the speaker is constructed. This is the third act, which is a pragmatic act. This includes agency construction as well: a certain level of agency is thereby constructed as a consequence of a particular transitivity pattern.

When the speaker utters the next clause, s/he performs the three acts again. It is likely that s/he may re-position her/his identity (agency) under the influence of another set of socio-cultural factors. The new identity (agency) positioning leads to different discursive (transitivity pattern) choices, and then to identity (agency) re-construction again. Each clause follows the previous one by a certain type of logico-semantic (LS) relation, sometimes marked by linguistic markers. It is through these LS relations that the speaker navigates among different identities, or different levels of agency.

Drawing on this theoretical framework, a working definition for agency has been provided to guide the current research. Agency is defined as a dynamic sense of control over the world. It is an identity dilemma, in which the individual constantly constructed and negotiated a relationship with the world. It is discursively constructed and navigated, and mediated by socio-cultural structures.

As shown in the theoretical framework, agency is realized at the level of the individual clause. To be more specific, agency is operationalized as the transitivity pattern of a clause within narratives, i.e., the configuration of a clause, including who is positioned as doing which kind of things, in relation to what, or whom. Different transitivity patterns will create different levels of agency. Through these analyses, we can explore how the individuals present themselves as "doing things" or "being engaged" in events in their narratives.

\section{Research Design}

\subsection{Research Questions}

The current study aims to investigate the discursive construction and navigation of agency in oral narratives of English learning by Chinese college English majors. The study is going to address two research questions, each consisting of two sub-questions: 
Q1. How do the speakers construct different levels of agency in their narratives?

Q1-1.What transitivity patterns are used within individual clauses to construct a high level of agency?

Q1-2.What transitivity patterns are used within individual clauses to construct a low level of agency?

Q2. How do the speakers navigate among different levels of agency throughout their narratives?

Q2-1.What logico-semantic relations are used between clauses to turn agency up or down?

Q2-2.What logico-semantic relations are used between clauses to maintain an agency level?

The two research questions will be answered through fine linguistic analysis of the English-learning stories told by Chinese college English majors.

\subsection{Methodology}

All the participants are English majors from the Faculty of English Language and Culture (FELC) in GW. The author has followed them for one year. She met them individually once a month and asked them to tell her stories, sharing their desires, fears, joys and frustrations in English learning. Then the author listened to the recordings again and again with the purpose of choosing the most significant stories for analysis. They need not be dramatic events, but they must in some way have had a significant impact on the personal and professional learning of the participants

Once a significant story was selected, it was transcribed and analyzed. This stage consists of two parts: transitivity analysis (including both transitive and ergative analyses) for agency construction and LS analysis for agency navigation. Based on the transitivity patterns with the reliability check by other analysts, the agency level constructed in each clause is determined with the author's interpretation. The results from the preliminary interpretation were then provided to the narrator him/herself for credibility check in a follow-up interview. After the agency level for each clause had been settled, the general transitivity patterns that are used to construct different levels of agency were deduced. Based on the agency level of each clause, the LS relations for realizing agency turns between clauses were also be deduced. The research design is illustrated by the following flowchart (see Figure 2).

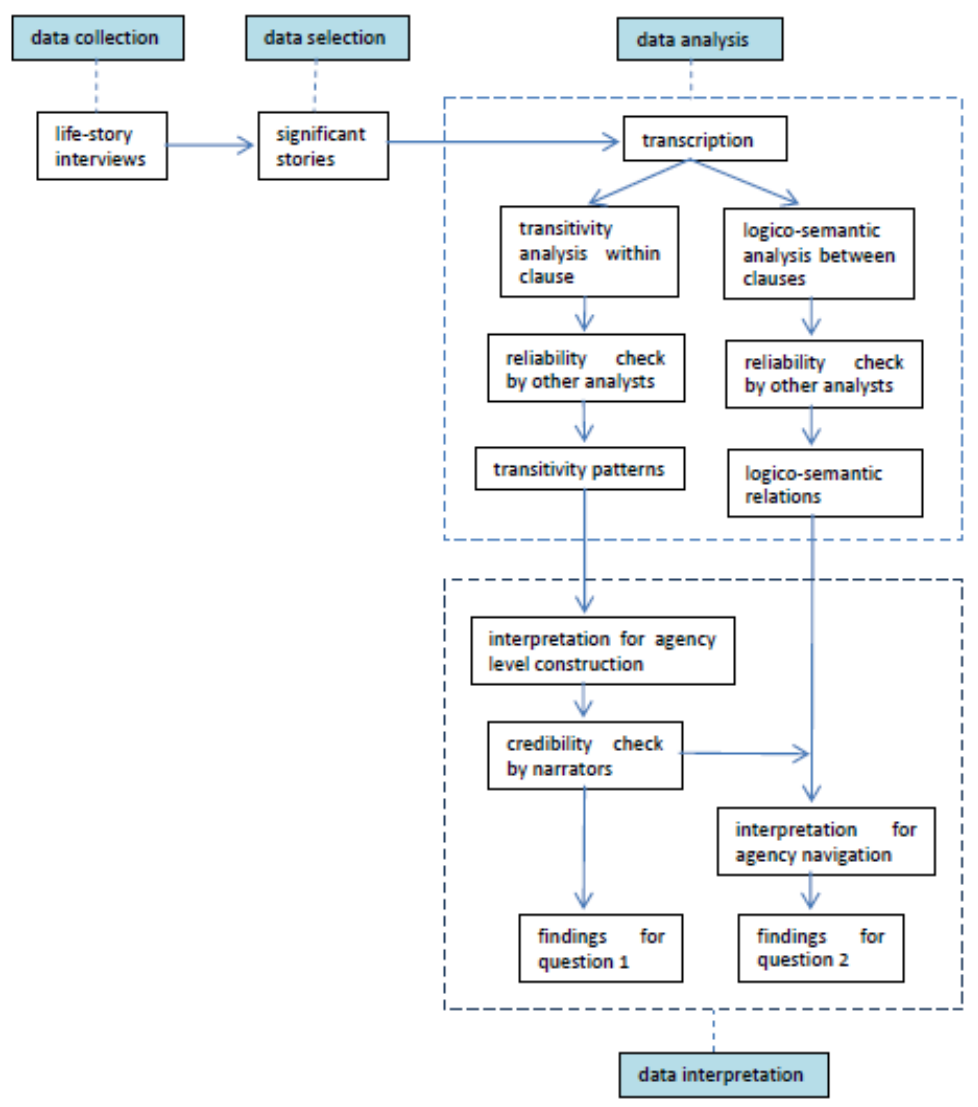

Figure 2. Research design 


\section{Analyses \& Findings}

This section is to demonstrate how the narrative data is analyzed and interpreted with an excerpt of one of the significant stories. The story-teller Vivian (pseudonym) is an active and out-going girl. At the time of the interview in June, 2014, she was towards the end of her second year in university, and has just participated in a drama contest. In the interview, Vivian told the author her story about joining the contest. The following excerpt is from her narrative, which was originally in the language of Chinese. For the ease of non-Chinese readers, the excerpt has been translated into English, while the syntactic structure and the lexical sequence of the original Chinese have been maintained.

\section{Excerpt from narrative by Vivian (female, sophomore)}

\section{English Translation}

I took part in the drama contest on June 6 . The drama contest, as we all know, is a traditional event in FELC. I think, as (I am)a student in FELC, (I) should ... the I myself like participating in these activities. Therefore I entered my name for it. During this contest, although I was just an actress, and (I) participated in it as a minor role, but each, each rehearsal had to be attended. Originally, what I interviewed for is a leading role, but after all (it) is a contest for third-year students, so the leading actors and actresses are generally the juniors. Then the director finally assigned me to a minor role. At that time I also have another engagement, so I thought, as (I was) unable to play a leading role, (being arranged) to play a minor role had not much bearing in fact, as long as it wouldn't take up too much of my time, since I was quite busy at that time. However, after I really got in, I felt that it did take up much time. This is not the point. The point is I have gained a lot. The core members of the crew have influenced me deeply, especially the director. He is an enterprising person. The script is, the adapters adapted (the script) from the classical Shakespeare's play. I read through the script. (I) really envy (them). (I) really admire them. They are able take English as a tool of their own. I think they are awesome. I think, if I am able to reach their level, (I) would be content. After I got in, a great change in me is, as I view it, English leaning is not a burden. (If I) am able to master English, and take it as a tool that I am able to use skillfully, for me (it) is happiness. I like English better and better.

\subsection{Agency Construction}

The transitivity analysis is now applied to this excerpt (see Table 1). First, the text is broken down into clauses in the first column. Second, the process type (with its sub-type) and participant roles (with the transitive model in the second and third columns) are identified for each clause. Then each participant is re-analyzed with the ergative model, labeled in ergative roles in the fourth column in the same row. Finally, the clause is examined all the way through the agency system (agency, voice, and agentivity) in the fifth column with ":" showing the hierarchy of delicacy. As examples, the analyses of the first three clauses and the $16^{\text {th }}$ clause of the text have been demonstrated in Table 1.

Table 1. Transitivity analysis of the excerpt

\begin{tabular}{|c|c|c|c|c|}
\hline \multirow[t]{2}{*}{ Clause } & \multicolumn{2}{|c|}{ Transitive Analysis } & \multirow{2}{*}{$\begin{array}{l}\text { Ergative } \\
\text { Analysis }\end{array}$} & \multirow{2}{*}{$\begin{array}{l}\text { Agency } \\
\text { Analysis }\end{array}$} \\
\hline & process type & participants & & \\
\hline$/ 1 /$ the I took part in the & material: & $\mathrm{I}=$ Actor & $=$ Agent & effective: \\
\hline drama contest on June 6 & transformative & drama contest $=$ Scope & $=$ Range & operative \\
\hline$/ 2 /<<$ as we all know $>>$ & $\begin{array}{l}\text { mental: } \\
\text { cognitive }\end{array}$ & we $=$ Sensor & $=$ Medium & $\begin{array}{l}\text { effective: } \\
\text { operative }\end{array}$ \\
\hline $\begin{array}{l}/ 3 / \text { the drama contest }<<\text { as } \\
\text { we all know }>>\text { is a } \\
\text { traditional event in FELC }\end{array}$ & $\begin{array}{l}\text { relational: } \\
\text { identifying }\end{array}$ & $\begin{array}{l}\text { drama contest }=\text { Token } \\
\text { traditional contest }=\text { Value }\end{array}$ & $\begin{array}{l}=\text { Medium } \\
=\text { Range }\end{array}$ & $\begin{array}{l}\text { effective: } \\
\text { operative }\end{array}$ \\
\hline $\begin{array}{l}/ 16 / \text { then the director } \\
\text { finally assigned me to a } \\
\text { minor role }\end{array}$ & $\begin{array}{l}\text { relational: } \\
\text { identifying }\end{array}$ & $\begin{array}{l}\text { director }=\text { Assigner } \\
\mathrm{I}=\text { Token } \\
\text { minor role }=\text { Value }\end{array}$ & $\begin{array}{l}=\text { Agent } \\
=\text { Medium } \\
=\text { Range }\end{array}$ & $\begin{array}{l}\text { effective: } \\
\text { operative }\end{array}$ \\
\hline
\end{tabular}

With the transitivity analysis as shown in table 1 , the agency level constructed in each clause is to be determined. 
Clause /1/ has the Actor "I", the Scope "drama contest" and the process of "participation". In this clause Vivian constructs an agentive role for herself by indicating that she participated in the event actively. It is the speaker who takes the initiative to act upon the event. So it is "high" in agency. Clause $/ 2 /$ is a cognitive mental clause as an introducer for what the speaker knows or thinks. While what the speaker knows or thinks (the objective clause) may be agentive sometimes, the introducer itself is judged as "neutral" in agency here. Clause $/ 3 /$, the objective clause, is also "neutral" in agency as it is a mere description of fact. Now let's look at clause $/ 16 /$, a clause with strong feature of low agency. It has three participants: Token, Value and Assigner - "I" is the Token, and "a minor role" is the Value. But this relation is not assigned by "I", but by the director. So the director is the Assigner who assigns the Value to the Token. In Ergative model, "the director" is the Agent, "I" is the Medium, and "a minor role" is the Range. By appointing the Agent explicitly in the clause, the process becomes highly effective. The director is presented as the external agency for this process (my playing of a minor role), and "I" am just the medium through whom this process is actualized.

From the analysis and interpretation above and after the credibility check with Vivian herself in a follow-up interview, the excerpt is annotated by each clause being attached with an agency level $(\mathrm{H}, \mathrm{N}$, or L) (see appendix). Now it can be summarized how Vivian configured clauses to construct deferent levels of agency in this excerpt. A high level of agency is constructed by:

1) operative material process with "I" as the Actor and Agent

e.g. "I took part in the drama contest on June 6" /1/ (figure in / / indicates clause number)

2) emotive mental process to express a sense of pleasure or contentment

e.g. "I myself like participating in these activities" /7/

3) attributive relational process assigning "I' with attributes of "competence" (including in imagination or condition)

e.g. "if I am able to master English" /48/

A low level of agency is constructed by:

1) desiderative mental process to imply a sense of obligation

e.g. "I should..." /6/; “(I) really envy them"/36/

2) attributive relational process assigning the narrator with attributes of "incapability" or "powerlessness" and assigning "others" with attributes of "competence" or "controlling"

e.g. "as (I was) unable to play a leading role"/19/; "he is an enterprising person"/32/

3) operative material process appointing the Agent explicitly in the clause and the narrator as the Medium through whom this process is actualized

e.g. "then the director finally assigned me to a minor role"/16/; "the core members of the crew have influenced me deeply"/30/

4) receptive material process with a hidden external Agent

e.g. "but each, each rehearsal had to be attended"/11/

\subsection{Agency Navigation}

In this excerpt there are 16 clauses at high agency level, 22 clauses at low agency level, and 14 clauses being neutral in agency (see Appendix). The agency fluctuations can be visualized by the following line chart (see Figure 3).

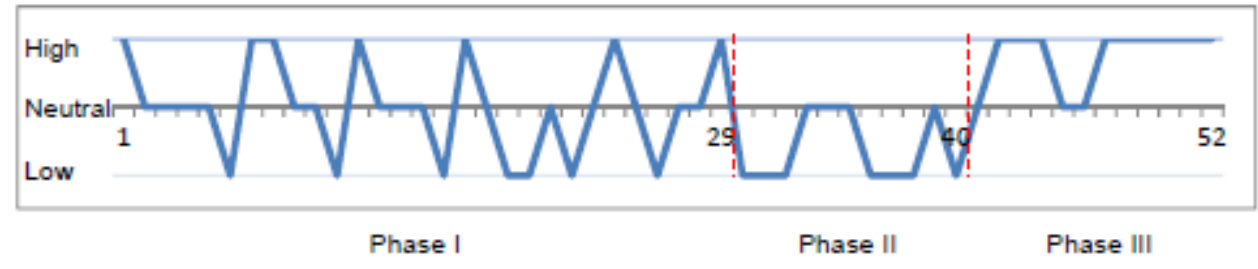

Figure 3. Agency fluctuations in the excerpt 
There are three distinct phases in this excerpt. Agency fluctuates quite violently during phase of the excerpt from clause /1/ to /29/, in which Vivian talked about why she took part in the drama contest, why she played a minor role, and how she consoled herself into accepting the minor role. Then agency keeps a relatively low level in phase II from $/ 30 /$ to $/ 40 /$, in which Vivian talked about how she felt after becoming a member of the cast. In the last phase, by contrast, agency turns up from /41/ to /52/ in which Vivian expressed her desires for English learning.

But how exactly are these agency fluctuations achieved? What LS relations are there to realize the agency turns? Now LS analysis is applied to the excerpt to give the answer (see Table 2). First, all clauses are listed again in the second column. Then the clauses are grouped into clause-complexes in the first column according to the topic-relatedness of the neighboring clauses. Next the LS relation is identified for every successive pair of clauses in each clause complex in the third column. The first clause in each complex is not assigned any relation as it is considered as topically distant from the preceding clause and it starts a new complex. Finally in the fourth column, the agency level (which has been settled in section 5.1) is attached to each clause so that it is more convenient to see whether the agency level turns up or down or maintains the same. As examples again, the first three clauses (as the first clause-complex) have been shown in table 2 .

Table 2. Logico-semantic analysis of the excerpt

\begin{tabular}{|c|c|c|c|}
\hline Clause-Complex & Clause & $\begin{array}{l}\text { LS Relation between } \\
\text { Clauses }\end{array}$ & $\begin{array}{l}\text { Agency } \\
\text { Level }\end{array}$ \\
\hline \multirow[t]{3}{*}{$/ / \mathrm{A} / /$} & /1/ I took part in the drama contest on June 6 & N/A & $\mathrm{H}$ \\
\hline & $12 /<<$ as we all know $>>$ & $\begin{array}{l}\text { expansion: } \\
\text { clarification }\end{array}$ & $\mathrm{N}$ \\
\hline & $\begin{array}{l}/ 3 / \text { the drama contest }<<\text { as we all know }>>\text { is a } \\
\text { traditional event in FELC }\end{array}$ & projection: reported idea & $\mathrm{N}$ \\
\hline
\end{tabular}

From the analysis above it can be summarized how Vivian organized successive clauses to navigate among different levels of agency in this excerpt. The common LS relations to turn agency up or down include:

1) expansion: extending : addition : adversative

For example, agency turns from neutral in "and I participated in it as a minor role" /10/ to low in "but each, each rehearsal, I had to attend"/11/.

2) expansion : extending : variation : replacive

For example, agency turns from low in "(I) should ..." /6/ to high in "I myself like participating in these activities" $/ 7 /$.

3) expansion : enhancing : temporal : later

For example, agency turns from high in "however, after (I) really got in (the contest)" $/ 24 /$ to neutral in "I felt that" /25/ and then down to low in "it did take up much time" $/ 26 /$.

4) expansion: extending : addition : additive

For example, by juxtaposing two kinds of feelings together, agency turns from low in "they are awesome" /40/ to high in "if I am able to reach their level /42/, I would be content /43/".

The common LS relations to maintain the agency level include:

1) expansion: extending : addition : additive

For example, the low agency in "(I) really envy (them)" /36/ is passed on to "(I) really admire (them)" /37/ by the progressive relation between the clauses.

2) expansion : elaborating : exemplification

For example, the low agency in "the core members of the crew have influenced me deeply" $/ 30 /$ is reinforced by the example in "especially the director (has influenced me deeply)" $/ 31 /$.

3) expansion : elaborating : clarification

For example, the high agency in "especially the director (has influenced me deeply)" $/ 31$ / is reinforced by the 
clarification of what kind of the person the director is in "he is an enterprising person" $/ 32 /$.

4) expansion : elaborating : exposition

For example, the low agency in "(if I) am able to master English" /48/ is kept in another way of wording in "and take it as a tool" $/ 49 /$.

5) expansion : enhancing : cause : result

For example, the high agency in "I myself like participating in these activities" $/ 7 /$ is maintained in the result in "therefore I entered my name for (the contest)" $/ 8 /$.

6) expansion : enhancing : condition : positive/negative

For example, the high agency in the condition in "if I am able to reach their level" /42/ remains in the consequence in "I would be content" /43/.

\section{Conclusion}

The study aims to obtain a "thick" discursive description of agency making and its dynamics in oral narratives from the lens of systematic functional linguistics. Although this paper only demonstrates with one example how the study is conducted and shows part of results, the most typical ways of configurations and connections of individual clauses in agency making and negotiation have been found. With more significant stories being analyzed and interpreted, more transitivity patterns for agency constructions and more logico-semantic relations for agency navigation will be added. The number of the stories for selection and analysis depends on whether the findings become repetitive. If the discursive patterns have been recurring in new stories and no more new patterns occur, no more stories will be collected and chosen for analysis.

Through transitivity analysis and LS analysis to the English-learning stories told by Chinese college English majors, the study has found that speakers construct different levels of agency with various transitivity patterns, and navigate among different levels of agency with various logico-semantic relations. It has also illustrated that agency is not a fixed entity that a speaker possesses, but constructed and negotiated dynamically by the speaker all the way through his/her narratives.

It should be noted that what the study reveals is the agency levels discursively constructed by the speakers in their narratives, which may not truthfully represent the agency levels deep inside the speakers. Sometimes it is likely that a speaker tells his/her story in a particular way purposefully in order to construct a proactive or a passive image in front of others. In these cases, it is impossible to explore his/her real psychological world just based on what $\mathrm{s} / \mathrm{he}$ says and how $\mathrm{s} / \mathrm{he}$ says it. What has been discussed about discursive choices as the result of agency positionings is on the basis of spontaneous and unconscious expressions without intentional hiding or distorting the truth.

\section{References}

Ahearn, L. M. (2001). Language and agency. Annual Review of Anthropology, 30,109-137. https://doi.org/10.1146/annurev.anthro.30.1.109

Bamberg, M., De Fina, A., \& Schiffrin, D. (2011).Discourse and identity construction. In S. Schwartz, K. Luyckx, \& V. Vignoles (Eds.), Handbook of identity theory and research. Berlin/New York: Springer Verlag. https://doi.org/10.1007/978-1-4419-7988-9_8

Bamberg, M., \& Georgakopoulou, A. (2008). Small stories as a new perspectivein narrative and identity analysis. Text \& Talk, 28, 377-396. https://doi.org/10.1515/TEXT.2008.018

Barker, C., \& Galasiński, D. (2001). Cultural Studies and Discourse Analysis: A Dialogue on Language and Identity. London: Sage.

Barkhuizen, G. (2013). Narrative Research in Applied Linguistics. Cambridge: Cambridge University Press.

Comparini, L. (2013). The use of justifications in the linguistic construction ofagency and social connection in $\begin{array}{lllll}\text { Latina mother--child conflict. Journal of Pragmatics, 57, } & \text { 57. }\end{array}$ https://doi.org/10.1016/j.pragma.2013.07.007

Eggins, S. (2005). An Introduction to Systemic Functional Linguistics (2nd ed.) Continuum.

Franzosi, R., De Fazio, G., \& Vicari, S. (2012). Ways of measuring agency: an application of quantitative narrative analysis to Lynchings in Georgia (1875-1930). Sociological Methodology, 42, 1-42. https://doi.org/10.1177/0081175012462370

Halliday, M. A. K. (1975). Learning How to Mean. London: Edward Arnold. 
https://doi.org/10.1016/B978-0-12-443701-2.50025-1

Halliday. M. A. K. (1979). Modes of meaning and modes of expression: types of grammatical structure and their determination by different semantic functions. In D. J. Allerton, E. Carney, \& D. Addcroft (Eds.), Function and Context in Linguistics Analysis. Cambridge: Cambridge University Press.

Halliday, M. A. K., \& Matthiessen, C. (2008). An Introduction to Functional Grammar (3rd ed.). Beijing: Foreign Language Teaching and Research Press.

Huang, J., \& Benson, P. (2013). Autonomy, Agency and Identity in Foreignand Second Language Education. Chinese Journal of Applied Linguistics, 36, 6-27.

King, B. (2014). Inverting virginity, abstinence, and conquest: Sexual agency and subjectivityin classroom conversation. Sexualities, 17, 310-328. https://doi.org/10.1177/1363460713516337

Lieblich, A., Zilber, T., \& Tuval-Mashiach, R. (2008). Narrating Human Actions: The Subjective Experience of Agency,Structure, Communion, and Serendipity. Qualitative Inquiry, 14, 613-631. https://doi.org/10.1177/1077800408314352

Lipponen, L., \& Kumpulainen, K. (2011). Acting as accountable authors: Creating interactional spaces for agency work in teacher education. Teaching and Teacher Education, 27, 812-819. https://doi.org/10.1016/j.tate.2011.01.001

Matthiessen, C. (2002a). Combining clauses into clause complexes: Amulti-faceted view. In J. Bybee, \& M. Noonan (Eds.), Complex sentences ingrammar and discourse: Essays in honor of Sandra A. Thompson. Amsterdam: Benjamins. https://doi.org/10.1075/z.110.13mat

Matthiessen, C. (2002b). Lexicogrammar in discourse development: Logogenetic patterns of wording. In G. Huang, \& Z. Wang (Eds.), Discourse andlanguage functions. Shanghai: Foreign Language Teaching and Research Press.

Matthiessen, C. (2009). Meaning in the Making: Meaning PotentialEmerging From Acts of Meaning. Language Learning, 59, 206-229. https://doi.org/10.1111/j.1467-9922.2009.00541.x

Miller, E. (2010). Agency in the Making: Adult Immigrants' Accounts of Language Learning and Work. TESOL Quarterly, 44, 465-487. https://doi.org/10.5054/tq.2010.226854

Nguyen, H. (2012). Transitivity Analysis of "Heroic Mother" by Hoa Pham. International Journal ofEnglish Linguistics, 2, 85-100. https://doi.org/10.5539/ijel.v2n4p85

Qin, L. (2015). Relationships between English Learner Agency and Identity in Socio-cultural Perspective. Foreign Language Education, 36, 60-64.

Schiffrin, D. (1996). Narrative as self-portrait: The sociolinguistic construction of identity. Language in Society. 25, 167-203. https://doi.org/10.1017/S0047404500020601

Strauss. S, \& Xiang, X. (2006). The Writing Conference as a Locus of Emergent Agency. Written Communication, 23, 355-396. https://doi.org/10.1177/0741088306292286

Thompson, G. (2008). Introducing Functional Grammar. Beijing: Foreign Language Teaching and Research Press.

\section{Appendix}

\section{Annotation of the excerpt}

I took part in the drama contest on June $6 / 1 \mathrm{H} /$. The drama contest, as we all know $/ 2 \mathrm{~N} /$, is a traditional event in FELC $/ 3 \mathrm{~N} /$. I think $/ 4 \mathrm{~N} /$, as (I am) a student in FELC $/ 5 \mathrm{~N} /$, (I) should .../6L/ I myself like participating in these activities $/ 7 \mathrm{H} /$. Therefore I entered my name for it $/ 8 \mathrm{H} /$. During this contest, although I was just an actress $/ 9 \mathrm{~N} /$, and (I) participated in it as a minor role $/ 10 \mathrm{~N} /$, but each, each rehearsal had to be attended $/ 11 \mathrm{~L} /$. Originally, what I interviewed for $/ 12 \mathrm{~N} /$ is a leading role $/ 13 \mathrm{H} /$, but after all (it) is a contest for third-year students $/ 14 \mathrm{~N} /$, so the leading actors and actresses are generally the juniors $/ 15 \mathrm{~N} /$. Then the director finally assigned me to a minor role $/ 16 \mathrm{~L} /$. At that time I also have another engagement $/ 17 \mathrm{H} /$, so I thought $/ 18 \mathrm{~N} /$, as (I was) unable to play a leading role $/ 19 \mathrm{~L} /$, (being arranged) to play a minor role $/ 20 \mathrm{~L} /$ had not much bearing in fact $/ 21 \mathrm{~N} /$, as long as it wouldn't take up too much of my time $/ 22 \mathrm{~L} /$, since I was quite busy at that time $/ 23 \mathrm{~N} /$. However, after I really got in $/ 24 \mathrm{H} /$, I felt that $/ 25 \mathrm{~N} /$ it did take up much time $/ 26 \mathrm{~L} /$. This is not the point $/ 27 \mathrm{~N} /$. The point is $/ 28 \mathrm{~N} / \mathrm{I}$ have gained a lot $129 \mathrm{H} /$. The core members of the crew have influenced me deeply $/ 30 \mathrm{~L} /$, especially the director $/ 31 \mathrm{~L} /$. He is an 
enterprising person $/ 32 \mathrm{~L} /$. The script is $/ 33 \mathrm{~N} /$, the adapters adapted (the script) from the classical Shakespeare's play $/ 34 \mathrm{~N} /$. I read through the script $/ 35 \mathrm{~N} /$. (I) really envy (them) $/ 36 \mathrm{~L} /$. (I) really admire them $/ 37 \mathrm{~L} /$. They are able take English as a tool of their own $/ 38 \mathrm{~L} /$. I think $/ 39 \mathrm{~N} /$ they are awesome $/ 40 \mathrm{~L} /$. I think $/ 41 \mathrm{~N} /$, if I am able to reach their level $/ 42 \mathrm{H} /$, (I) would be content $/ 43 \mathrm{H} /$. After I got in $/ 44 \mathrm{H} /$, a great change in me is $/ 45 \mathrm{~N} /$, as I view it $/ 46 \mathrm{~N} /$, English leaning is not a burden $/ 47 \mathrm{H} /$. (If I) am able to master English $/ 48 \mathrm{H} /$, and take it as a tool /49H/ that I am able to use skillfully $/ 50 \mathrm{H} /$, for me (it) is happiness $/ 52 \mathrm{H} /$. I like English better and better $/ 52 \mathrm{H} /$.

*Note: The excerpt is annotated by attaching an agency level $(\mathrm{H}, \mathrm{N}$, or L) to the end of each clause immediately after the clause number.

\section{Copyrights}

Copyright for this article is retained by the author(s), with first publication rights granted to the journal.

This is an open-access article distributed under the terms and conditions of the Creative Commons Attribution license (http://creativecommons.org/licenses/by/4.0/). 